Subscriber access provided by Caltech Library

\title{
Article
}

\section{Highly Stable Organic Bisradicals Protected by Mechanical Bonds}

Kang Cai, Haochuan Mao, Wei-Guang Liu, Yunyan Qiu, Yi Shi, Long Zhang, Dengke

Shen, Hongliang Chen, Yang Jiao, Huang Wu, ZHICHANG LIU, Yuanning Feng,

Charlotte L. Stern, Michael R. Wasielewski, William A. Goddard, and J. Fraser Stoddart

J. Am. Chem. Soc., Just Accepted Manuscript • DOI: 10.1021/jacs.0c01989 • Publication Date (Web): 30 Mar 2020

Downloaded from pubs.acs.org on March 30, 2020

\section{Just Accepted}

"Just Accepted" manuscripts have been peer-reviewed and accepted for publication. They are posted online prior to technical editing, formatting for publication and author proofing. The American Chemical Society provides "Just Accepted" as a service to the research community to expedite the dissemination of scientific material as soon as possible after acceptance. "Just Accepted" manuscripts appear in full in PDF format accompanied by an HTML abstract. "Just Accepted" manuscripts have been fully peer reviewed, but should not be considered the official version of record. They are citable by the Digital Object Identifier (DOI@). "Just Accepted" is an optional service offered to authors. Therefore, the "Just Accepted" Web site may not include all articles that will be published in the journal. After a manuscript is technically edited and formatted, it will be removed from the "Just Accepted" Web site and published as an ASAP article. Note that technical editing may introduce minor changes to the manuscript text and/or graphics which could affect content, and all legal disclaimers and ethical guidelines that apply to the journal pertain. ACS cannot be held responsible for errors or consequences arising from the use of information contained in these "Just Accepted" manuscripts. 


\section{Highly Stable Organic Bisradicals Protected by}

\section{Mechanical Bonds}

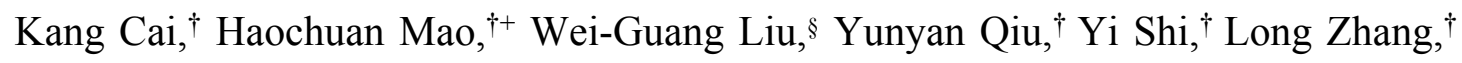
Dengke Shen,${ }^{\dagger}$ Hongliang Chen,${ }^{\dagger}$ Yang Jiao,$^{\dagger}$ Huang Wu,$^{\dagger}$ Zhichang Liu ${ }^{\perp}$, Yuanning Feng, ${ }^{\dagger}$ Charlotte L. Stern, ${ }^{\dagger}$ Michael R. Wasielewski, ${ }^{\dagger+}$ William A. Goddard III, ${ }^{\S}$ J. Fraser Stoddart $\$ \# *$

${ }^{\dagger}$ Department of Chemistry, Northwestern University, 2145 Sheridan Road, Evanston, Illinois 60208, United States

${ }^{+}$Institute for Sustainability and Energy at Northwestern, Northwestern University, 2145 Sheridan Road, Evanston, Illinois 60208, United States

${ }^{\S}$ Materials and Process Simulation Center, California Institute of Technology, Pasadena, CA 91125, USA

${ }^{\perp}$ School of Science, Westlake University, 18 Shilongshan Road, Hangzhou 310024, China

¥Institute for Molecular Design and Synthesis, Tianjin University, 92 Weijin Road, Tianjin 300072, China

"School of Chemistry, University of New South Wales, Sydney, NSW 2052, Australia

\section{ABSTRACT}

Two new highly charged [2]catenanes-namely, $\boldsymbol{m H e}[2] \mathbf{C} \cdot 6 \mathrm{PF}_{6}$ and

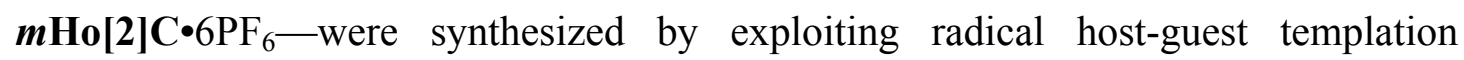
between BIPY $^{\bullet+}$ derivatives and $\boldsymbol{m} \mathbf{C B P Q T}^{2(\bullet+)}$. In contrast to related [2]catenanes that have been isolated as air-stable monoradicals, both $m \mathbf{H e}[2] \mathbf{C}_{\bullet} 6 \mathrm{PF}_{6}$ and $m \mathbf{H o}[2] \mathbf{C} \cdot 6 \mathrm{PF}_{6}$, exist as air-stable singlet bisradicals as evidenced by both X-ray crystallography in the solid state and EPR spectroscopy in solution. Electrochemical studies indicate that the first two reduction peaks of these two [2]catenanes are shifted significantly to more positive potentials, a feature which is responsible for their extraordinary stability in air. The mixed-valence nature of the mono- and bisradical states endows them with unique NIR-absorption properties, e.g., NIR absorption bands for the mono- and bisradical states observed at $\sim 1800$ and $\sim 1450 \mathrm{~nm}$, respectively. These [2]catenanes are potentially useful in applications that include NIR photothermal conversion, UV/Vis/NIR multiple-state electrochromic materials, and multiple-state memory devices. Our findings highlight the principle of "mechanical-bond-inducedstabilization" as an efficient strategy for designing persistent organic radicals. 


\section{INTRODUCTION}

In recent decades, the development of new stable organic radicals has become a topic for extensive investigations ${ }^{1,2}$ because of their unique optical, ${ }^{3}$ electronic, ${ }^{4}$ and magnetic ${ }^{5}$ properties. Most organic radicals are unstable under ambient conditions and dimerize $^{6}$ quickly — to form new covalent bonds — or become oxidized/reduced under ambient conditions, making their isolation and characterization demanding tasks. In general, there are several common strategies for enhancing the air-stability of organic radicals, such as (i) increasing the steric hindrance around the radical center ${ }^{7}$ in order to prevent dimerization, (ii) introducing electron-withdrawing groups to lower the LUMO energy level ${ }^{8}$ in order to enhance resistance to oxidation by $\mathrm{O}_{2}$ and $\mathrm{H}_{2} \mathrm{O}$, and (iii) recovering aromaticity ${ }^{9}$, amidst other exmaples ${ }^{1}$.

$N, N^{\prime}$-Disubstituted-4,4'-bipyridinium dications $\left(\mathbf{B I P Y}^{2+}\right)$, also known as viologens, are a class of intensively investigated ${ }^{10}$ electron acceptors that can undergo two sequential and reversible one-electron reductions with half-wave potentials of -0.30 and $-0.71 \mathrm{~V}$ (versus $\mathrm{Ag} / \mathrm{AgCl}$ in $\mathrm{MeCN}$ ). The bipyridinium radical cation $\left(\mathbf{B I P Y}{ }^{\bullet+}\right.$ ), which is generated from the one-electron reduction of $\mathbf{B I P Y}^{2+}$, is a well-known thermally stable radical species in an inert atmosphere, and can undergo (noncovalent) $\pi$-dimerization ${ }^{11}$ on account of radical-radical interactions; such interactions have been exploited intensively in supramolecular chemistry ${ }^{12}$ and mechanostereochemistry ${ }^{13}$. Although, BIPY $^{\circ+}$ cannot undergo $\sigma$-dimerization to form a covalent bond, it is unstable when exposed to air because the $\mathbf{B I P Y}^{2+} / \mathbf{B I P Y}^{\bullet+}$ reduction potential $(-0.30 \mathrm{~V}$ versus $\mathrm{Ag} / \mathrm{AgCl}$ ) is not sufficiently positive for the radicals to resist aerobic oxidation. It follows that tuning the reduction potential of viologens towards more positive values is desirable. A straightforward way to achieve this objective involves introducing electron-withdrawing substituents onto viologen derivatives that makes them more electron-deficient, as exemplified (Scheme 1) by tetramethyl esters functionalized ${ }^{14}$ dimethyl viologen, TEMV ${ }^{2+}$. The first reduction potential of $\mathbf{T E M V}^{2+}$ is shifted to 
around $+0.27 \mathrm{~V}$ versus $\mathrm{Ag} / \mathrm{AgCl}$ relative to that $(-0.30 \mathrm{~V})$ of the original dimethyl viologen radical cation $\left(\mathbf{M V}^{\bullet+}\right)$, and so the air-stability of the $\mathbf{T E M V} \mathbf{\bullet}^{\bullet+}$ radical cation turned out to be improved ${ }^{14}$ significantly.

a)

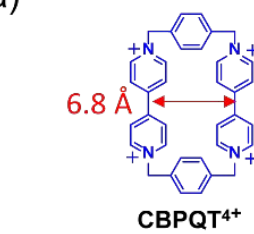

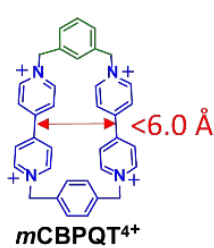

$m \mathrm{CBPQT}^{4+}$ b)

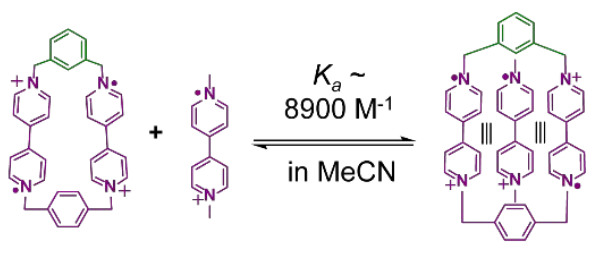

c)

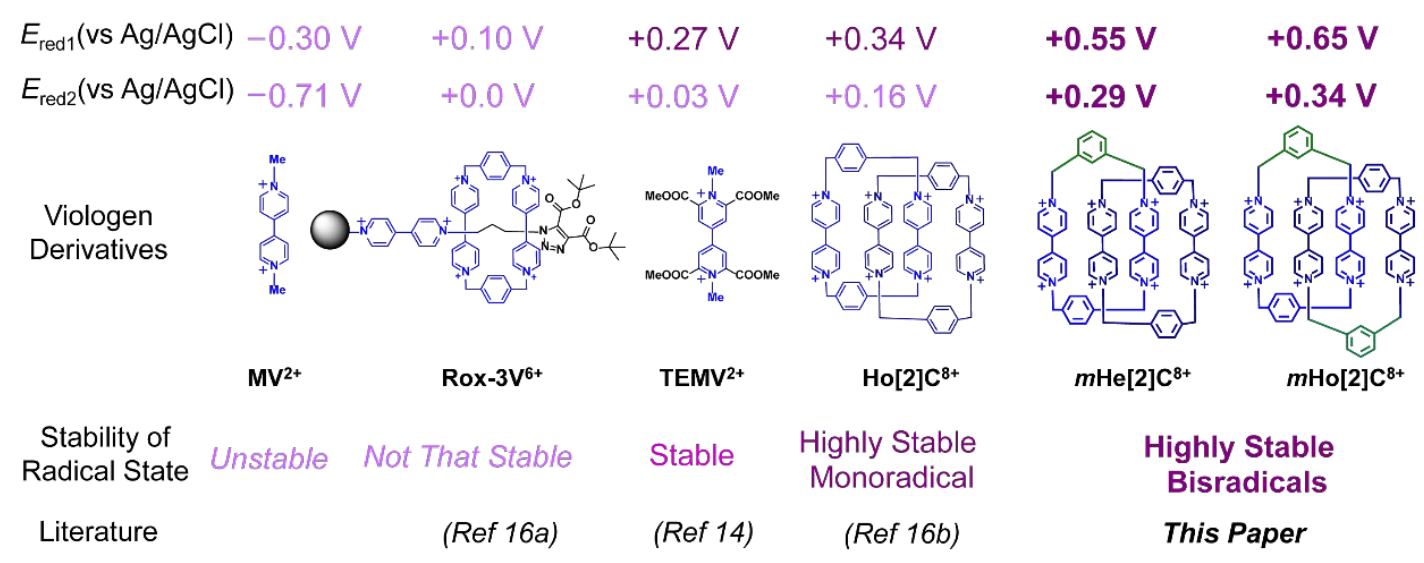

Scheme 1. a) Structural formulas and cavity sizes of $\mathrm{CBPQT}^{4+}$ and $\mathrm{mCBPQT}^{4+}$. b) The radical host-guest pairing interactions between $\mathbf{m C B P Q T ^ { 2 ( + ) }}$ and the dimethyl viologen radical cation, and the corresponding association constant $\left(K_{\mathrm{a}}\right)$ in $\mathrm{MeCN}$. c) The reduction potentials, radical stability, and corresponding reference literature of different viologen derivatives — including the newly designed [2]catenanes $\boldsymbol{m} \mathbf{H e}[2] \mathbf{C}^{8+}$ and $m \mathbf{H o}[2] \mathbf{C}^{8+}$-indicating the positive correlation between the reduction potential, and stability of the radicals.

Previously, we have discovered ${ }^{15}$ that the cyclobis(paraquat- $p$-phenylene) bisradical dication CBPQT $^{\mathbf{2}(+)}$, shown in Scheme 1a, can accommodate a BIPY ${ }^{\bullet+}$ radical cation to form the trisradical tricationic complex $\mathbf{B I P Y}^{{ }^{++}} \subset \mathbf{C B P Q T}^{\mathbf{2}(+)}$ in $\mathrm{MeCN}$. Using this complex as a templating motif, we have synthesized ${ }^{16}$ a series of highly positively charged mechanically interlocked molecules (MIMs), i.e., Rox-3V $\mathbf{6}^{\mathbf{}}$ and Ho[2] $\mathbf{C}^{8+}$ shown in Scheme 1c. We found that the reduction potentials of these MIMs are shifted to significantly more positive values when the positively charged components in the 
MIMs are forced into nano-confinement as a result of mechanical bonding which stabilizes the radical states under ambient conditions. This property is especially evident in the homo[2]catenane, $\mathbf{H o}[2] \mathbf{C}^{\mathbf{8}}$, in which the four repulsive viologen units are obliged to stack with $\pi$-overlap in a very small volume $\left(<1.25 \mathrm{~nm}^{3}\right)$, a situation that brings about a strong tendency for $\mathbf{H o}[2] \mathbf{C}^{8+}$ to accept electrons, resulting in the stabilization of the monoradical $\mathbf{H o}[2] \mathbf{C}^{\cdot 7+}$ state under ambient conditions.

Recently, we found ${ }^{17}$ that $\boldsymbol{m} \mathbf{C B P Q T}^{\mathbf{2}(\cdot)}$, which is a constitutional isomer of CBPQT $^{2(\bullet+)}$, also associates with $\mathbf{M V}^{\bullet+}$ in $\mathrm{MeCN}$, despite its cavity being significantly smaller (Scheme 1a and 1b) than that present in CBPQT ${ }^{2(+)}$. Hence, we have become interested in making new [2] catenanes $^{18}$ - namely $m \mathbf{H e}[2] C^{8+}$ and $m \mathbf{H o}[2] C^{8+}$ (Scheme $1 \mathrm{c}$ ) - using $m \mathrm{CBPQT}^{4+}$ in their component rings. Since the $m \mathrm{CBPQT}^{4+}$ cavity is smaller ${ }^{17}$ than that of $\mathrm{CBPQT}^{4+}$, the four electrostatically repulsive viologen units stack in an even more compact manner than those present in $\mathbf{H o}[2] \mathbf{C}^{8+}$. Consequently, both of the two inner BIPY ${ }^{2+}$ units in $m \mathbf{H e}[2] \mathbf{C}^{8+}$ and $m \mathbf{H o}[2] \mathbf{C}^{8+}$ are expected to be more easily reduced than those in $\mathbf{H o}[2] \mathbf{C}^{8+}$. If the second reduction potentials of $\boldsymbol{m} \mathbf{H e}[2] \mathbf{C}^{8+}$ and $\boldsymbol{m} \mathbf{H o}[2] \mathbf{C}^{8+}$ are shifted positively to values that make aerobic oxidation difficult, ${ }^{19}$ then the bisradical forms - namely, $\boldsymbol{m} \mathbf{H e}[2] \mathbf{C}^{\mathbf{2} \cdot \mathbf{6 +}}$ and $\boldsymbol{m} \mathbf{H o}[\mathbf{2}] \mathbf{C}^{\mathbf{2} \cdot \mathbf{6 +}}$ - will be stable under ambient conditions. Herein, we report the synthesis and characterization of these two mechanical-bond-protected, air-stable organic bisradicals.

\section{RESULTS AND DISCUSSION}

\section{Synthesis}

The highly stable bisradical [2]catenanes, $\boldsymbol{m H e}[2] \mathbf{C} \cdot 6 \mathrm{PF}_{6}$ and $\boldsymbol{m H o [ 2 ] C} \cdot 6 \mathrm{PF}_{6}$, were synthesized by modifying the previously reported procedure ${ }^{16 \mathrm{~b}}$ for the preparation of Ho[2]C·7PF 6 . The $\mathbf{m C B P Q T} \cdot 4 \mathrm{PF}_{6}$ host and the guest molecule $\mathbf{1} \cdot 2 \mathrm{PF}_{6}$ were reduced (Scheme 2) with an excess of $\mathrm{Cu}$ dust in $\mathrm{MeCN}$ in a $\mathrm{N}_{2}$-filled glovebox for $2 \mathrm{~h}$, producing the trisradical tricationic inclusion complex $\mathbf{1}^{\bullet+} \subset \mathbf{m C B P Q T} \mathbf{C}^{2(\bullet+)} .4,4^{\prime}-$ Bipyridine was then added to this solution so as to react with $1 \cdot 2 \mathrm{PF}_{6}$ and give 
$m \mathbf{H e}[2] \mathrm{C}^{3 \cdot 5+}$ as the ring-closure product, which was then reduced again by the $\mathrm{Cu}$ dust $^{20}$ to give $\boldsymbol{m} \mathrm{He}[2] \mathbf{C}^{4(\cdot)}$. The reaction mixture was stirred at room temperature under $\mathrm{N}_{2}$ for 1 week, after which it was exposed to air. Purification by reverse phase column chromatography, followed by counterion exchange, and recrystallization (see Supporting Information Section B) afforded $\boldsymbol{m H e}[2] \mathbf{C} \cdot 6 \mathrm{PF}_{6}$ in $30 \%$ yield. In a similar manner, $\boldsymbol{m H o}[2] \mathbf{C} \cdot 6 \mathrm{PF}_{6}$ was obtained in $19 \%$ yield by reacting $\boldsymbol{m} \mathbf{C B P Q T} \cdot 4 \mathrm{PF}_{6}$ with $\mathbf{2} \cdot 3 \mathrm{PF}_{6}$ using the same protocol. The lower yield of $\mathbf{m H o}[2] \mathbf{C} \cdot 6 \mathrm{PF}_{6}$ can be attributed to the smaller cavity of $\mathbf{m} \mathbf{C B P Q T}^{\mathbf{2 ( + \bullet )}}$ compared to that of $\mathbf{C B P Q T}^{\mathbf{2 ( + \bullet})}$, which renders the ring-closure step for $\boldsymbol{m} \mathbf{H o}[2] \mathbf{C} \cdot 6 \mathrm{PF}_{6}$ more difficult than that for $\boldsymbol{m H e}[2] \mathbf{C} \cdot 6 \mathrm{PF}_{6}$. High resolution electrospray ionization mass spectrometry (ESI-MS) confirmed that both catenanes possess the same molecular formula, i.e., $\mathrm{C}_{72} \mathrm{H}_{64} \mathrm{~F}_{36} \mathrm{~N}_{8} \mathrm{P}_{6}$. See Supporting Information. ${ }^{1} \mathrm{H}$ NMR Spectra (Figure S1 and S3) have been recorded for both catenanes in their fully oxidized states — namely, $\boldsymbol{m H e}[2] \mathbf{C} \cdot 8 \mathrm{PF}_{6}$ and $\boldsymbol{m H o}[2] \mathbf{C} \cdot 8 \mathrm{PF}_{6}$ which were obtained by oxidizing the as-synthesized catenanes with an excess of $\mathrm{NOPF}_{6} \cdot$ Because of their lower symmetries, both $\boldsymbol{m} \mathbf{H e}[2] \mathbf{C} \cdot 8 \mathrm{PF}_{6}$ and $\boldsymbol{m} \mathbf{H o}[2] \mathbf{C} \cdot 8 \mathrm{PF}_{6}$ display much more complicated ${ }^{1} \mathrm{H}$ NMR spectra than that observed (Figure S5) for Ho[2]C $\cdot 8 \mathrm{PF}_{6}$. The characteristic signals of these [2] catenanes correspond to the proton resonances of the innermost $\mathrm{BIPY}^{2+}$ units, which are strongly shielded and consequently shifted dramatically upfield, into the $4-5 \mathrm{ppm}$ region. Notably, the eight resonances for the innermost protons are separated into two sets of signals for $\boldsymbol{m H e}[2] \mathbf{C} \cdot 8 \mathrm{PF}_{6}$ (two protons resonate at $\sim 5.10 \mathrm{ppm}$ and six protons resonate at $\sim 4.25$ ppm), while these same eight proton resonances in the spectrum of $\mathbf{m H o}[2] \mathbf{C} \cdot 8 \mathrm{PF}_{6}$ are separated into four sets of signals at 5.29, 4.98, 4.38, and $4.07 \mathrm{ppm}$. These observations can be attributed to the asymmetric cavities of the $m \mathrm{CBPQT}^{4+}$ component ring(s). The encapsulated BIPY ${ }^{2+}$ unit(s) are obliged to reside closer to the $p$-xylylene linker end than the $m$-xylylene linker end in order to attenuate Coulombic repulsions as much as possible. As a consequence, the innermost protons on the BIPY ${ }^{2+}$ units of $m \mathrm{CBPQT}^{4+}$ experience different extents of shielding, leading to well separated chemical shifts. The remaining proton resonances in the spectra of $\boldsymbol{m} \mathbf{H e}[2] \mathbf{C} \cdot 8 \mathrm{PF}_{6}$ and $\boldsymbol{m} \mathbf{H o}[2] \mathbf{C} \cdot 8 \mathrm{PF}_{6}$ are 
also more complicated for similar reasons.

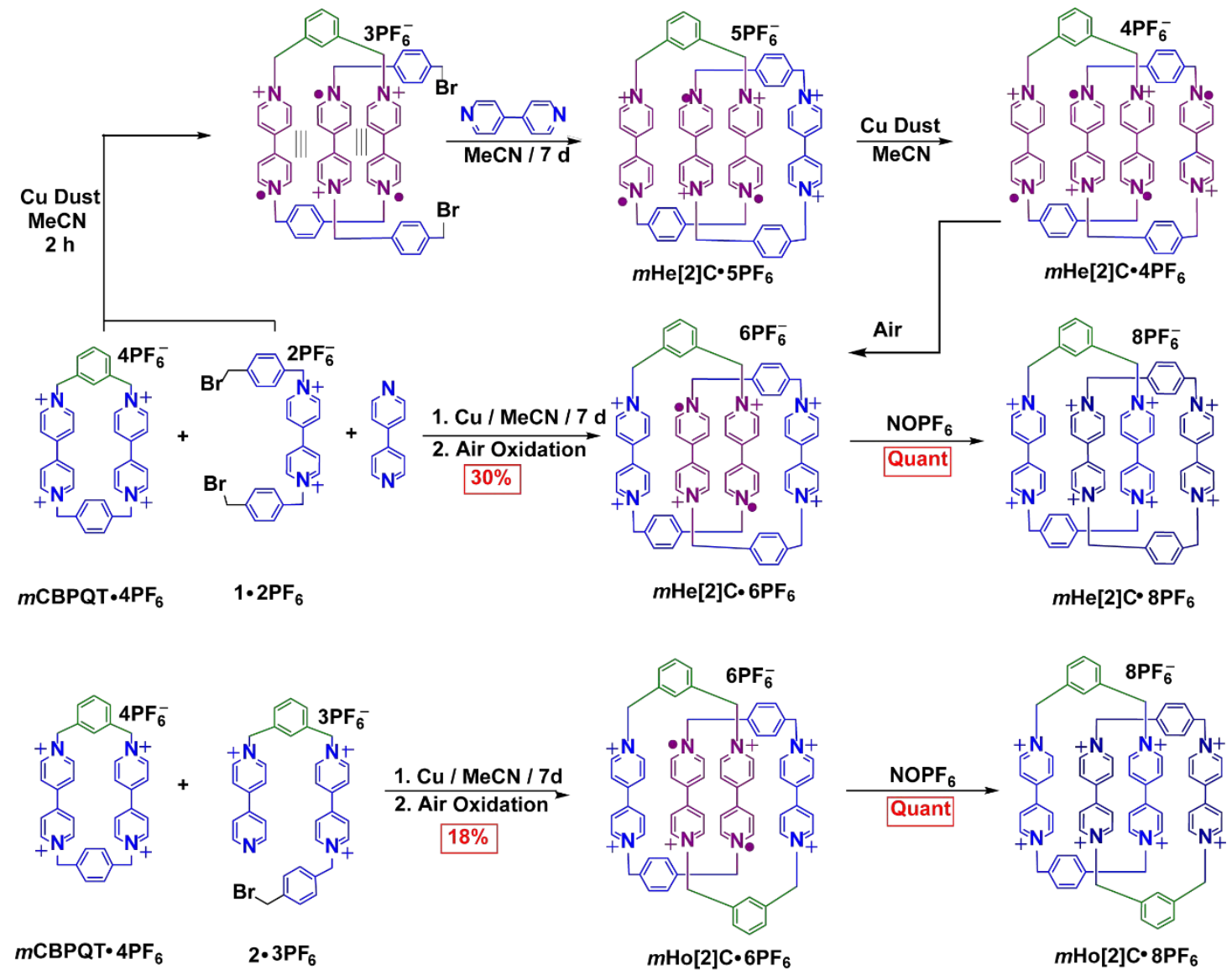

Scheme 2. Synthetic route for the preparation of $m \mathrm{He}[2] \mathrm{C} \cdot 6 \mathrm{PF}_{6}, m \mathrm{Ho}[2] \mathrm{C} \cdot 6 \mathrm{PF}_{6}$, $m \mathrm{He}[2] \mathrm{C} \cdot 8 \mathrm{PF}_{6}$ and $\boldsymbol{m} \mathbf{H o}[2] \mathrm{C} \cdot 8 \mathrm{PF}_{6}$.

\section{X-Ray Crystallography}

Single crystals of the two catenanes were grown under ambient conditions by slowly evaporating $\mathrm{Et}_{2} \mathrm{O}$ into $1.0 \mathrm{mM} \mathrm{MeCN}$ solutions over a week which affords dark red crystals suitable for X-ray crystallographic analysis. The solid-state structures show

(Figure 1) that both compounds crystallize with six $\mathrm{PF}_{6}{ }^{-}$counterions around the catenanes, an observation which confirms their bisradical hexacationic states under ambient conditions. The torsional angles (Figure $1 \mathrm{~b}$ ) of $20^{\circ}$ and $23^{\circ}$ for the $\mathrm{A}$ and $\mathrm{D}$ units, respectively, in $\boldsymbol{m} \mathbf{H e}[2] \mathbf{C}^{2 \cdot 6+}$ are typical of dicationic BIPY ${ }^{2+}$ units, and indicate that the unpaired electrons are not located on the A and D units. By contrast, units B and $\mathrm{C}$ show (Figure $1 \mathrm{~b}$ ) much smaller torsion angles $-8^{\circ}$ for unit $\mathrm{B}$ and $6^{\circ}$ for unit $\mathrm{C}-$ 
indicating that the unpaired electrons are most likely to be located between these units.

a)

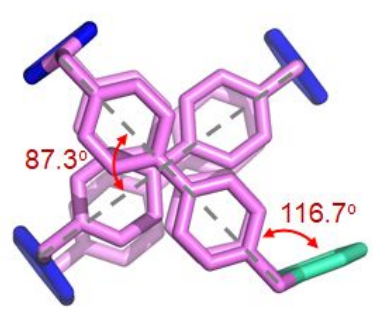

d)

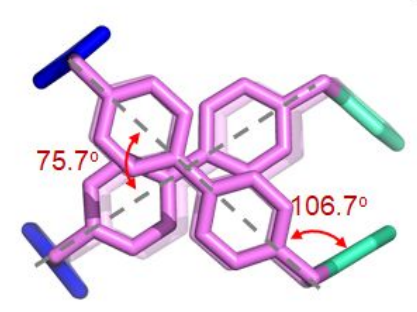

b)

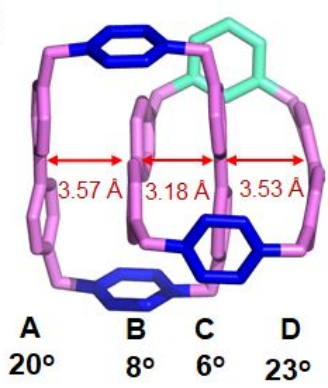

e)

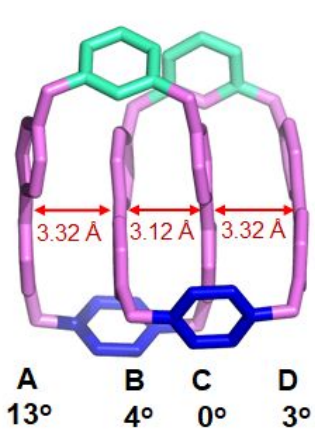

c)

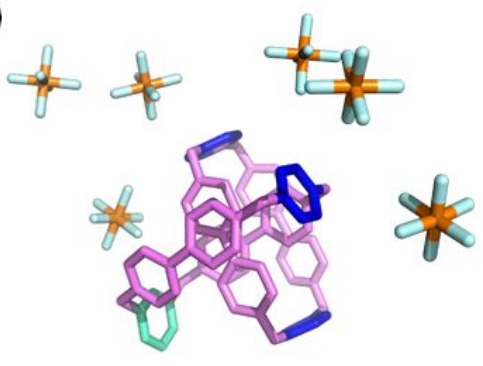

f)

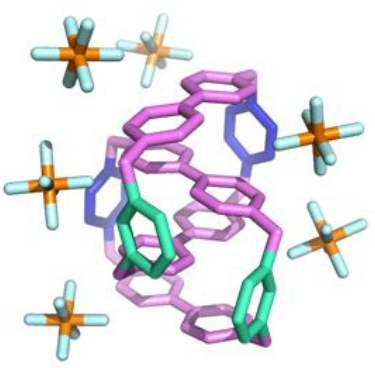

Figure 1. Solid-state structures. a) A side-on view showing the dihedral angle between the BIPY units in $\boldsymbol{m} \mathbf{H e}[2] \mathbf{C}^{2 \cdot 6+}$. b) A top-down view showing the distances and the torsion angles between stacked units in $\boldsymbol{m} \mathbf{H e}[2] \mathbf{C}^{2 \cdot 6+}$. c) A side-on view showing that there are six $\mathrm{PF}_{6}{ }^{-}$anions surrounding every $\boldsymbol{m} \mathbf{H e}[2] \mathbf{C}^{\mathbf{2} \cdot 6+}$. d) A side-on view showing the dihedral angle between the BIPY units in $\boldsymbol{m} \mathbf{H o}[2] \mathbf{C}^{\mathbf{2} \cdot \boldsymbol{6}+}$. e) A top-down view showing the distances and the torsion angles between stacked units in $\boldsymbol{m} \mathbf{H o}[2] \mathbf{C}^{2 \cdot 6+}$. f) A side-on view showing that there are six $\mathrm{PF}_{6}{ }^{-}$anions surrounding every $\mathbf{m} \mathbf{H o}[2] C^{2 \cdot 6+}$.

Moreover, the centroid-to-centroid distance $(3.18 \AA)$ between units $\mathrm{B}$ and $\mathrm{C}$ is significantly shorter than that observed between $(3.57 \AA)$ units A and B or between $(3.53 \AA)$ units $\mathrm{C}$ and $\mathrm{D}$. The value of the distance $(3.18 \AA)$ between units $\mathrm{B}$ and $\mathrm{C}$ is a typically associated with radical-radical interactions, an observation that supports the existence of radical-radical pairing interactions between units B and C. In the case of $\boldsymbol{m H o} \mathbf{2}] \mathbf{C}^{2 \cdot 6+}$, however, all four units (A, B, C, and D) present (Figure 1e) near planar conformations with somewhat smaller $\left(<13^{\circ}\right)$ torsion angles, as well as shorter $(<3.57$ $\AA$ ) distances between adjacent units when compared to those in $\mathbf{m H e}[\mathbf{2}] \mathbf{C}^{\mathbf{2} \boldsymbol{6}^{+}}$. These observations can be explained by the small cavities of the two $m$ CBPQT rings, which 
force the four viologen units to stack more tightly in $m \mathbf{m o}[2] C^{2 \cdot 6+}$ than in $m \mathbf{H e}[2] C^{2 \cdot 6+}$, thereby leading to flatter viologen-unit conformations and shorter separations. Nevertheless, the torsion angles of the two inner units, $\mathrm{B}\left(4^{\circ}\right)$ and $\mathrm{C}\left(0^{\circ}\right)$, are still smaller than those of the outer units, $\mathrm{A}\left(13^{\circ}\right)$ and $\mathrm{D}\left(3^{\circ}\right)$, while the centroid-to-centroid distance (3.12 $\AA$ ) between units $\mathrm{B}$ and $\mathrm{C}$ is also smaller than that between $(3.39 \AA)$ units A and B or between $(3.34 \AA)$ units C and D. Therefore, we conclude that the two spins in $\boldsymbol{m H o}[2] \mathbf{C}^{\mathbf{2 \cdot 6 +}}$ are also mainly located on units B and C.

\section{Electrochemistry}

Since the stabilities of viologen radicals in air are mainly determined by their potentials, the redox properties of $m \mathbf{H e}[2] \mathrm{C} \cdot 6 \mathrm{PF}_{6}$ and $m \mathbf{H o}[2] \mathrm{C} \cdot 6 \mathrm{PF}_{6}$ were investigated by cyclic voltammetry $(\mathrm{CV})$. The $\mathrm{CV}$ curve for $\boldsymbol{m} \mathbf{H e}[2] \mathbf{C} \cdot 6 \mathrm{PF}_{6}$ exhibits (Figure 2) five reversible waves corresponding to six discrete accessible redox states, which are similar to those observed previously for $\mathbf{H o}[2] \mathbf{C} \cdot 7 \mathrm{PF}_{6}$. On the other hand, $\mathbf{m H o}[\mathbf{2}] \mathbf{C} \cdot 6 \mathrm{PF}_{6}$ displays (Figure 2) six reversible waves because of further splitting of its last reduction peaks. Notably, the first two reduction peaks of both $\boldsymbol{m} \mathbf{H e}[2] \mathbf{C}^{8+}\left(E_{\text {red1 }}=+0.56 \mathrm{~V}\right.$ and $E_{\text {red2 }}=$ $+0.29 \mathrm{~V}$ versus $\mathrm{Ag} / \mathrm{AgCl})$ and $\boldsymbol{m} \mathbf{H o}[2] \mathbf{C}^{8+}\left(E_{\text {red } 1}=+0.65 \mathrm{~V}\right.$ and $E_{\text {red2 }}=+0.34 \mathrm{~V}$ versus $\mathrm{Ag} / \mathrm{AgCl})$ are significantly positively shifted compared to those previously observed for $\mathbf{H o}[2] \mathbf{C}^{8+}\left(E_{\text {red1 }}=+0.34 \mathrm{~V}\right.$ and $E_{\text {red } 2}=+0.16 \mathrm{~V}$ versus $\left.\mathrm{Ag} / \mathrm{AgCl}\right)$. The LUMO energy levels of $\boldsymbol{m} \mathbf{H e}[2] \mathbf{C}^{8+}$ and $\boldsymbol{m} \mathbf{H o}[2] \mathbf{C}^{8+}$ which are calculated to be -5.17 and $-5.27 \mathrm{eV}$, respectively, both are much lower than those for tetracyanoquinodimethane $\left(\mathrm{E}_{\mathrm{LUMO}}=\right.$ $-4.84 \mathrm{eV}$ ) and some other ${ }^{2 \mathrm{~d}, 8}$ strong electron acceptors. This observation supports our hypothesis that decreasing the cavity sizes of the component-ring in these highly positively charged catenanes enhances their electron-accepting abilities. In addition, the last reduction peaks of $\boldsymbol{m} \mathbf{H e}[2] \mathbf{C}^{\mathbf{8}^{+}}\left(E_{\mathrm{red5}}=-1.31 \mathrm{~V}\right.$ versus $\left.\mathrm{Ag} / \mathrm{AgCl}\right)$ and $\boldsymbol{m} \mathbf{H o}[2] \mathbf{C}^{\mathbf{8}^{+}}$ $\left(E_{\text {red5 }}=-1.22 \mathrm{~V}\right.$ versus $\left.\mathrm{Ag} / \mathrm{AgCl}\right)$ are both negatively shifted compared to the last reduction peak of $\mathbf{H o}[2] \mathbf{C}^{\mathbf{8}+}\left(E_{\mathrm{red} 5}=-1.06 \mathrm{~V}\right.$ versus $\left.\mathrm{Ag} / \mathrm{AgCl}\right)$. Taken all together, these observations demonstrate clearly that subtle differences in the cyclophane linkers 
influence significantly the redox behavior of these highly positively charged [2]catenanes.
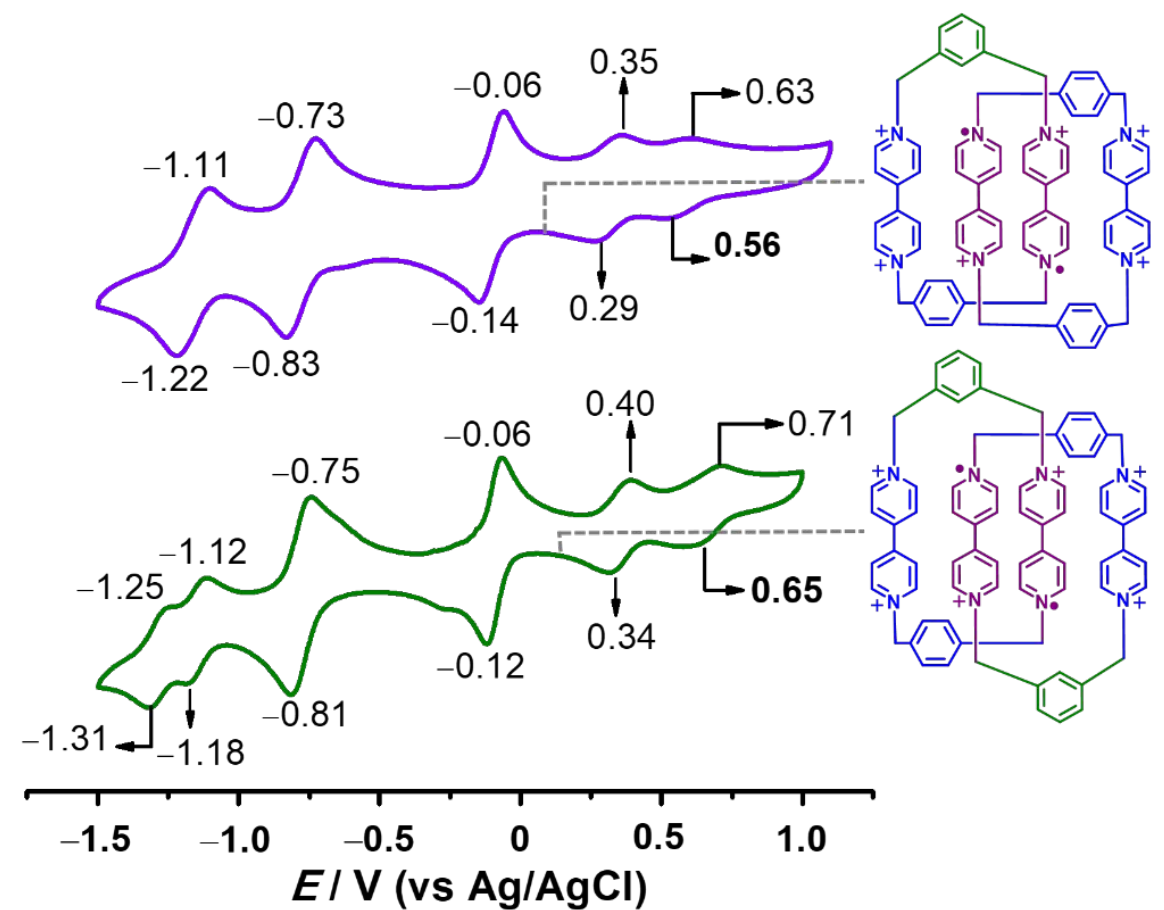

Figure 2. Cyclic voltammograms of $\boldsymbol{m H e}[2] \mathbf{C} \cdot 6 \mathrm{PF}_{6}(0.50 \mathrm{mM}$, blue trace $)$ and $\boldsymbol{m H o [ 2 ] C} \cdot 6 \mathrm{PF}_{6}(0.50 \mathrm{mM}$, green trace $)$ with the redox potentials marked on all peaks.

Significantly, the potentials of the second reduction peaks of $\mathbf{m H e}[2] \mathbf{C}^{\mathbf{8}}\left(E_{\text {red2 }}=+0.29\right.$ $\mathrm{V})$ and $\boldsymbol{m} \mathbf{H o}[2] \mathbf{C}^{\mathbf{8}}\left(E_{\text {red2 }}=+0.34 \mathrm{~V}\right)$ are comparable to the first reduction potentials of TEMV $^{2+}\left(E_{\text {red1 }}=+0.29 \mathrm{~V}\right.$, Scheme 1$)$ and Ho[2] $\mathbf{C}^{\mathbf{8}}\left(E_{\mathrm{red} 1}=+0.35 \mathrm{~V}\right.$, Scheme 1). Accordingly, the bisradical states of $m \mathrm{He}[2] C^{8+}$ and $m \mathbf{H o}[2] C^{8+}$ are very like to exhibit similar stabilities in air as $\mathbf{T E M V}^{\bullet+}$ and $\mathbf{H o}[2] \mathbf{C}^{\bullet 7+}$.

\section{UV-Vis-NIR Spectroscopy}

In order to gain additional insight into their electronic properties, we recorded the UVVis-NIR spectra of the two [2]catenanes in their various electrochemically generated redox states at different potentials. The $\mathrm{CV}$ traces (Figure 2) reveal that $\mathrm{MeCN}$ solutions of $\boldsymbol{m H e}[2] \mathrm{C} \cdot 6 \mathrm{PF}_{6}(+0.80,+0.42,+0.10$, and $-0.50 \mathrm{~V})$ and $\boldsymbol{m H o}[2] \mathbf{C} \cdot 6 \mathrm{PF}_{6}(+0.80$, $+0.50,+0.10$ and $-0.50 \mathrm{~V})$ require different potentials in order to generate the 
corresponding redox states $(8+, 7+, 6+$, and $4+)$. UV-Vis-NIR Spectra of the MeCN solutions of the $7+$ (monoradical), $6+$ (bisradical), and $4+$ (tetraradical) redox states were recorded. See Figure 3a, b. Notably, the mono- and bisradical states of both [2]catenanes exhibit NIR absorption bands around $1800 \mathrm{~nm}$ and $1440 \mathrm{~nm}$, respectively, and both of these absorptions are significantly red-shifted compared ${ }^{12 c}$ to those of $\mathrm{BIPY}^{\bullet+}$ (around $600 \mathrm{~nm}$ ) and the BIPY ${ }^{\bullet+} \ldots \mathrm{BIPY}^{\bullet+}$ supramolecular dimer $(800-900 \mathrm{~nm})$. By contrast, the tetracationic tetraradical states, only display NIR bands centered around $1070 \mathrm{~nm}$. These observations indicate that both the mono- and bisradical states are "mixed-valence" ones. Since all four BIPY units are so closely stacked (distances $<3.6 \AA ̊$ ), $\pi$-overlap and electronic communication exists between all four BIPY units. Consequently, the unpaired electrons of the radicals are shared by the four BIPY units to form mixed-valence states with significantly narrow bandgaps.
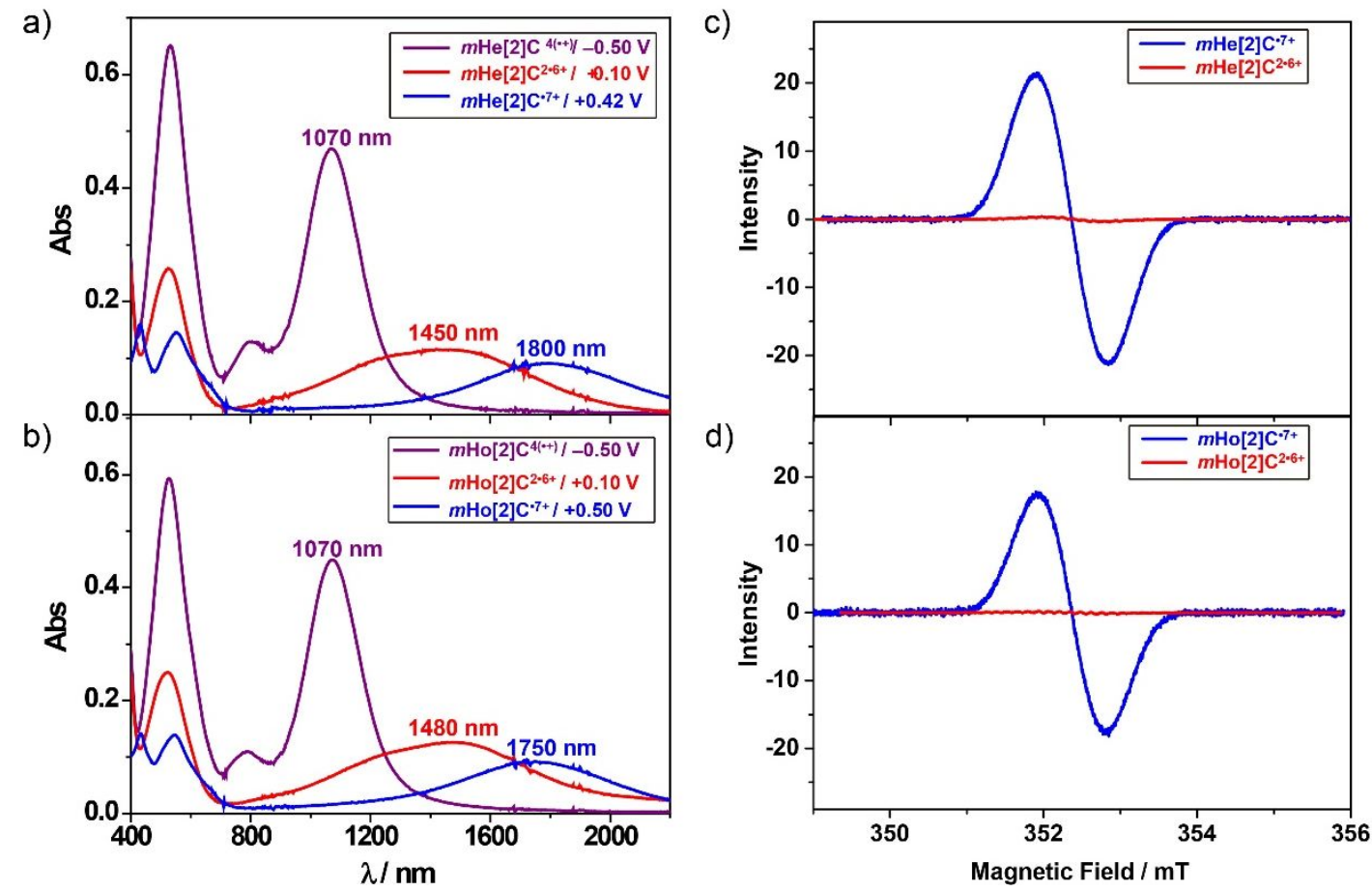

Figure 3. Vis/NIR Absorption spectra of the different redox states obtained employing electrochemical reduction at different voltages. a) Purple line: $\boldsymbol{m} \mathbf{H e}[2] \mathbf{C}^{4(\cdot)}(-0.50 \mathrm{~V})$; red line: $\boldsymbol{m} \mathbf{H e}[2] \mathbf{C}^{2 \cdot 6+}(+0.10 \mathrm{~V})$; blue line: $\boldsymbol{m} \mathbf{H e}[2] \mathbf{C}^{\cdot 7+}(+0.42 \mathrm{~V})$. b) Purple line: $\boldsymbol{m H o}[2] \mathbf{C}^{4(\cdot+)}(-0.50 \mathrm{~V})$; red line: $\boldsymbol{m H o}[2] \mathbf{C}^{2 \cdot 6+}(+0.10 \mathrm{~V})$; blue line: $\boldsymbol{m} \mathbf{H o}[2] \mathbf{C}^{\cdot 7+}$ $(+0.50 \mathrm{~V})$. Reference electrode: $\mathrm{Ag} / \mathrm{AgCl}$. c) EPR spectra of $\boldsymbol{m} \mathbf{H e}[2] \mathbf{C}^{\cdot 7+}$ (blue line) and $\boldsymbol{m H e}[2] \mathbf{C}^{2 \cdot 6+}$ (red line). d) EPR spectra of $\boldsymbol{m} \mathbf{H o}[2] \mathbf{C}^{\bullet 7+}$ (blue line) and $\boldsymbol{m} \mathbf{H o}[2] \mathbf{C}^{2 \cdot 6+}$ (red line). 
We also examined the stabilities of the tetra-, bis-, and monoradical states of the two [2]catenanes in air by time-dependent UV-Vis-NIR spectroscopy under ambient conditions. Upon exposure to air, the tetraradicals $\left(m \mathbf{H e}[2] C^{4(\cdot+)}\right.$ and $\left.m \mathbf{H o}[2] C^{4(\cdot+)}\right)$ in MeCN were observed (Figure S6 and S7) to decay gradually to their bisradical states $\left(\boldsymbol{m H e}[2] C^{2 \cdot 6+}\right.$ and $\left.m \mathbf{H o}[2] C^{2 \cdot 6+}\right)$ over several hours. The bisradicals $\left(\boldsymbol{m H e}[2] C^{2 \cdot 6+}\right.$ and $\boldsymbol{m} \mathbf{H o}[2] \mathbf{C}^{2 \cdot 6+}$ ), however, exhibit extraordinary stabilities under ambient conditions. MeCN solutions of $\boldsymbol{m} \mathbf{H e}[2] \mathbf{C}^{\mathbf{2 \cdot 6 +}}$ and $\boldsymbol{m} \mathbf{H o}[2] \mathbf{C}^{\mathbf{2} \cdot \boldsymbol{6}^{+}}$can be stored in air for more than ten days without any change (Figure S8 and S9) in their absorption spectra. Noteworthy is the fact that, although the monoradicals $\left(\boldsymbol{m H e}[2] \mathrm{C}^{\bullet 7+}\right.$ and $\left.m \mathbf{H o}[2] \mathrm{C}^{\bullet 7+}\right)$ are quite stable in their solid states, in some cases, they tend to be reduced into bisradicals in their solution states when stored in air for more than 1 weeks.

Organic NIR dyes with absorption bands longer than $1200 \mathrm{~nm}$ are not abundant ${ }^{3 b, 21}$, not only because such red-shifted absorptions are difficult to achieve, but also because organic compounds with extremely narrow bandgaps suffer from stability issues. Hence, our results show that, the mono- and bisradical states of these two [2]catenanes are promising air-stable NIR-absorbing dyes with significantly red-shifted absorption peaks of ca. 1800 and $1450 \mathrm{~nm}$.

\section{EPR Spectroscopy}

We also recorded (Figure 3c, d) the electron paramagnetic resonance (EPR) spectra of the bisradicals $\left(\boldsymbol{m} \mathbf{H e}[\mathbf{2}] \mathbf{C}^{\mathbf{2} \cdot \mathbf{6}^{+}}\right.$and $\left.\boldsymbol{m} \mathbf{H o}[\mathbf{2}] \mathbf{C}^{\mathbf{2 \cdot 6 +}}\right)$ in $\mathrm{MeCN}$. The very weak signals, which were observed, are almost negligible compared with the signal intensities of the monoradicals (Figure 3c, d) recorded under similar conditions. These observations are in accordance with previously reported ${ }^{16 \mathrm{~b}}$ results, indicating that the unpaired electrons in the bisradicals are coupled antiferromagnetically and exist as ground-state singlets. The relatively weak signals observed in the EPR spectra can be attributed to the thermally populated triplet states of the bisradicals. 

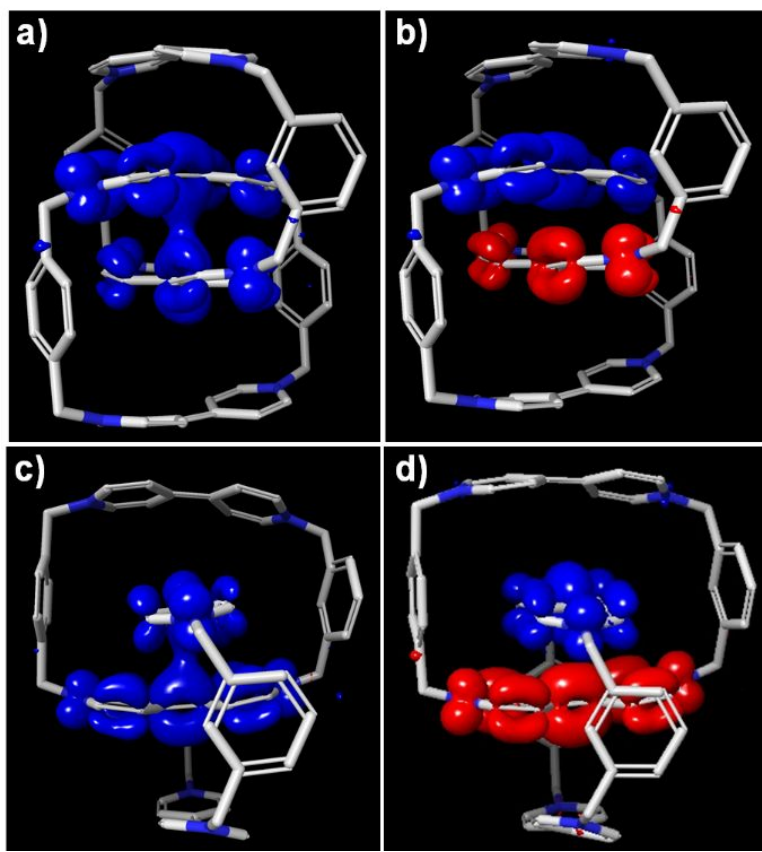

Figure 4. Spin-density distribution of: a) $m \mathrm{He}[2] C^{\cdot 7+}$; b) $m \mathrm{He}[2] C^{2 \cdot 6+}$; c) $m \mathrm{Ho}[2] C^{\cdot 7+}$; d) $\boldsymbol{m H o}[2] \mathbf{C}^{2 \cdot 6+}$, showing the spin densities are located in the two inner BIPY units for the two [2]catenanes in both mono- and bisradical states.

\section{DFT Calculations}

DFT calculations were performed in order to probe the electronic properties of the two catenanes. The results illustrate (Figure 4) that the spin densities in both mono$\left(m \mathrm{He}[2] C^{\cdot 7+}\right.$ and $\left.m \mathrm{Ho}[2] C^{\cdot 7+}\right)$ and bisradical $\left(m \mathrm{He}[2] C^{2 \cdot 6+}\right.$ and $\left.m \mathbf{H o}[2] C^{2 \cdot 6+}\right)$ states are located on their two innermost BIPY ${ }^{2+/ \bullet+}$ units in accordance with the experimental results. The theoretical association energies (Table S1) for the formation of catenanes in their different redox states $(\boldsymbol{m H e} \mathbf{H}] \mathbf{C}^{(\mathbf{8 - n}) \cdot \mathbf{n}+}$ and $\boldsymbol{m} \mathbf{H o}[2] \mathbf{C}^{(\mathbf{8 - n}) \cdot \mathbf{n}+}$, where $\mathrm{n}$ refers to the number of positive charges) from the corresponding cyclophanes were calculated in $\mathrm{MeCN}$ at the M06/6-311++G** level taking previous reported $\mathrm{Ho}^{* 2} \mathbf{C}^{(\mathbf{8}-\mathbf{n}) \cdot \mathbf{n}+}$ as the control molecule. For each of nine redox states, the theoretical association energy $(\Delta E)$ of $\boldsymbol{m H e}[\mathbf{2}] \mathbf{C}^{(\mathbf{8 - n}) \cdot \mathbf{n}+}$ and $\boldsymbol{m} \mathbf{H o}[2] \mathbf{C}^{(\mathbf{8}-\mathrm{n}) \cdot \mathbf{n}+}$ are always higher than the corresponding $\mathbf{H o}[2] \mathbf{C}^{(\mathbf{8 - n}) \cdot \mathbf{n}+}$, indicating that the introduction of $m \mathrm{CBPQT}$ ring into [2]catenanes is more energetically unfavorable than it is when the ring is CBPQT because of the smaller cavity size of $m$ CBPQT ring. Nevertheless, if we consider the binding energy difference $(\Delta \Delta E)$ between $7+$ and $8+$ state $\left(\Delta \Delta E=\Delta E_{7+}-\Delta E_{8+}\right)$, or $6+$ and $8+$ state 
$\left(\Delta \Delta E=\Delta E_{6+}-\Delta E_{8+}\right)$, a value which indicates the thermodynamic tendency of forming the $7+$ (monoradical) or $6+$ (bisradical) states from the reduction of state $8+$, the two new $m$ CBPQT-ring containing catenanes become energetically more favorable (Table S2) than that for $\mathbf{H o}[2] \mathbf{C}^{(\mathbf{8}-\mathbf{n}) \cdot \mathbf{n}+}$. Accordingly, the mono- and bisradical forms of $m$ CBPQT-ring-based [2]catenanes should exhibit enhanced stabilities compared with CBPQT-ring-based [2]catenane, an observation which is also in agreement with the experimental results.

\section{CONCLUSION}

Two new [2]catenanes, namely $\boldsymbol{m H e}[2] \mathbf{C} \cdot 6 \mathrm{PF}_{6}$ and $\boldsymbol{m H o [ 2 ] C} \cdot 6 \mathrm{PF}_{6}$, have been prepared by exploiting $\mathbf{m} \mathbf{C B P Q T}^{\mathbf{2}(\cdot)}$ as a host molecule using radical templation. On account of their significantly enhanced electron-accepting tendencies, both the mono$\left(m \mathrm{He}[2] \mathrm{C}^{\cdot 7+}\right.$ and $\left.m \mathrm{Ho}[2] \mathrm{C}^{\cdot 7+}\right)$ and bis- $\left(m \mathrm{He}[2] \mathrm{C}^{2 \cdot 6+}\right.$ and $\left.m \mathrm{Ho}[2] \mathrm{C}^{2 \cdot 6+}\right)$ radical states of these two catenanes exhibit extraordinary stabilities under ambient conditions. This finding highlights the effectiveness of the "mechanical-bond-induced-stabilization" strategy for preparing air-persistent organic radicals. The mixed-valence nature of the mono- and bisradical states is responsible for their unique NIR absorption properties. These new [2]catenanes are potentially useful in a variety of ways, such as in NIR-II photothermal conversion, ${ }^{22} \mathrm{UV} / \mathrm{Vis} / \mathrm{NIR}$ multistate electrochromic materials, ${ }^{23}$ and multistate information storage/memory devices ${ }^{24}$.

\section{ASSOCIATED CONTENT}

Detailed experimental sections, characterization data, and DFT calculations. The Supporting Information is available free of charge at https://pubs.acs.org/doi/xxxx/jacsxxx.

\section{AUTHOR INFORMATION}

Corresponding Author 
J. Fraser Stoddart - Northwestern University, Evanston, Illinois, Tianjin University, Tianjin, China, and University of New South Wales, Sydney, Australia; orcid.org/ 0000-0003-3161-3697; Email: stoddart@ northwestern.edu

\section{Notes}

The authors declare no competing financial interests.

\section{ACKNOWLEDGMENTS}

The authors thank Northwestern University (NU) for their support of this research. This work also made use of the IMSERC at Northwestern University, which has received support from the State of Illinois and International Institute for Nanotechnology (IIN). Z.L. acknowledges the support from the National Natural Science Foundation of China (No. 21971211) and the Supercomputer Center of Westlake University. The research at NU was also supported by National Science Foundation (NSF) grant no CHE1900422 (M.R.W.) The computational investigations at California Institute of Technology were supported by NSF grant no CBET-1805022.

\section{REFERENCES}

(1) (a) Sun, Z.; Wu, J. Open-shell polycyclic aromatic hydrocarbons. J. Mater. Chem. 2012, 22, 4151-4160; (b) Abe, M. Diradicals. Chem. Rev. 2013, 113, 7011-7088; (c) Tan, G.; Wang, X. Isolable bis(triarylamine) dications: analogues of Thiele's, Chichibabin's, and Muller's hydrocarbons. Acc. Chem. Res. 2017, 50, 1997-2006.

(2) (a) Konishi, A.; Hirao, Y.; Nakano, M.; Shimizu, A.; Botek, E.; Champagne, B.; Shiomi, D.; Sato, K.; Takui, T.; Matsumoto, K.; Kurata, H. Synthesis and characterization of teranthene: A singlet biradical polycyclic aromatic hydrocarbon having Kekule' structures. J. Am. Chem. Soc. 2010, 132, 11021-110239; (b) Pan, X.; Su, Y.; Chen, X.; Zhao, Y.; Li, Y.; Zuo, J.; Wang, X. Stable tetraaryldiphosphine radical cation and dication. J Am. Chem. Soc. 2013, 135, 5561-5564; (c) Schmidt, D.; Bialas, D.; Würthner, F. Ambient stable zwitterionic perylene bisimide-centered radical. Angew. Chem. Int. Ed. 2015, 54, 3611-3614; (d) Kumar, Y.; Kumar, S.; Mandal, K.; Mukhopadhyay, P. Isolation of tetracyano-naphthalenediimide and its 
stable planar radical anion. Angew. Chem. Int. Ed. 2018, 57, 16570-16570; (e) Zeng, W.; Gopalakrishna, T. Y., ; Phan, H.; Tanaka, T.; Herng, T. S.; Ding, J.; Osuka, A.; $\mathrm{Wu}$, J. Superoctazethrene: an open-shell graphene-like molecule possessing large diradical character but still with reasonable stability. J. Am. Chem. Soc. 2018, 140, 43, 14054-14058; (f) Rana, A.; Hong, Y.; Gopalakrishna, T. Y.; Phan, H.; Herng, T. S.; Yadav, P.; Ding, J.; Kim, D. Wu, J. Stable expanded porphycene-based diradicaloid and tetraradicaloid. Angew. Chem. Int. Ed. 2018, 57, 12534-12537; (g) Jiao, T.; Cai, K.; Nelson, J.N.; Jiao, Y.; Qiu, Y.; Wu, G.; Zhou, J.; Cheng, C.; Shen, D.; Feng, Y. Liu, Z.; Wasielewski, M. R.; Stoddart, J. F.; Li, H. Stabilizing the naphthalenediimide radical within a tetracationic cyclophane. J. Am. Chem. Soc. 2019, 141, 16915-16922.

(3) (a) Peng, Q.; Obolda, A.; Zhang, M.; Li, F. Organic light-emitting diodes using a neutral $\pi$ radical as emitter: The emission from a doublet. Angew. Chem. Int. Ed. 2015, 54, 7091-7095; (b) Ni, Y.; Wu. J. Diradical approach toward organic near infrared dyes. Tetrahedron Lett. 2016, 57, 5426-5434; (c) Ai, X.; Evans, E. W.; Dong, S.; Gillett, A. J.; Guo, H.; Chen, Y.; Hele, T. J.; Friend, R.H.; Li, F. Efficient radical-based light-emitting diodes with doublet emission. Nature, 2018, 563, 536.

(4) (a) Joo, Y.; Agarkar, V.; Sung, S. H.; Savoie, B. M.; Boudouris, B. W. A nonconjugated radical polymer glass with high electrical conductivity. Science, 2018, 359, 1391-1395; (b) Wang, P.; Lin, S.; Lin, Z.; Peeks, M. D.; Van Voorhis, T.; Swager, T. M. A semiconducting conjugated radical polymer: Ambipolar redox activity and Faraday Effect. 2018, 140, 34, 10881-10889; (c) London, A. E.; Chen, H.; Sabuj, M. A.; Tropp, J.; Saghayezhian, M.; Eedugurala, N.; Zhang, B. A.; Liu, Y.; Gu, X.; Wong, B. M.; Rai, N. A high-spin ground-state donor-acceptor conjugated polymer. Sci. Ad. 2019, 5, No. eaav2336.

(5) (a) Mahmood, J.; Park, J.; Shin, D.; Choi, H. J.; Seo, J. M.; Yoo, J. W.; Baek, J. B.; Organic ferromagnetism: trapping spins in the glassy state of an organic network structure. Chem, 2018, 4, 2357-2369; (b) Sugawara, T.; Komatsu, H.; Suzuki, K.; Interplay between magnetism and conductivity derived from spin-polarized donor radicals. Chem. Soc. Rev. 2011, 40, 3105-3118; (b) Phan, H.; Herng, T. S.; Wang, D.; Li, X.; Zeng, W.; Ding, J.; Loh, K. P.; Wee, A. T. S.; Wu, J. Room-temperature 
magnets based on 1,3,5-triazine-linked porous organic radical frameworks. Chem, 2019, 5, 1223-1234.

(6) (a) Chen, X.; Wang, X.; Zhou, Z.; Li, Y.; Sui, Y.; Ma, J.; Wang, X.; Power, P. P. Reversible $\sigma$-dimerizations of persistent organic radical cations. Angew. Chem. Int. Ed. 2013, 52, 589-592; (b) Zhao, D.; Fu, X. Cyclo-oligomerization of 6,12diethynyl indeno[1,2-b]fluorenes via diradical intermediates. Org. Lett. 2015, 17, 5694-5697; (c) Okino, K.; Hira, S.; Inoue, Y.; Sakamaki, D.; Seki, S. The divergent dimerization behavior of $N$-Substituted dicyanomethyl radicals: dynamically stabilized versus stable radicals. Angew. Chem. Int. Ed. 2017, 56, 16597-16601.

(7) (a) Zeng, Z.; Sung, Y. M.; Bao, N.; Tan, D.; Lee, R.; Zafra, J. L.; Lee, B. S.; Ishida, M.; Ding, J.; López Navarrete, J. T.; Li, Y. Stable tetrabenzo-Chichibabin's hydrocarbons: tunable ground state and unusual transition between their closedshell and open-shell resonance forms. J. Am. Chem. Soc. 2012, 134, 14513-14525. (b) Tian, Y.; Uchida, K.; Kurata, H.; Hirao, Y.; Nishiuchi, T.; Kubo, T. Design and synthesis of new stable fluorenyl-based radicals. J. Am. Chem. Soc. 2014, 136, 12784-12793.

(8) Kumar, S.; Ajayakumar, M.R.; Hundal, G.; Mukhopadhyay, P. Extraordinary stability of naphthalenediimide radical ion and its ultra-electron-deficient precursor: Strategic role of the phosphonium group. J Am. Chem. Soc. 2014, 136, $12004-12010$.

(9) (a) Zeng, Z.; Shi, X.; Chi, C.; Navarrete, J. T. L.; Casado, J.; Wu, J. Pro-aromatic and anti-aromatic $\pi$-conjugated molecules: An irresistible wish to be diradicals. Chem. Soc. Rev. 2015, 44, 6578-6596; (b) Liu, C.; Ni, Y.; Lu, X.; Li, G.; Wu, J. Global aromaticity in macrocyclic polyradicaloids: Hückel's Rule or Baird's Rule? Acc. Chem. Res. 2019, 52, 2309-2321.

(10) (a) Michaelis, L.; Hill, E.S. The viologen indicators. J. Gen. Physiol. 1933. 16, 859-873; (b) Hünig, S. Stable radical ions. Pure Appl. Chem. 1967, 15, 109-122; (c) Kosower, E. M.; Hajdu, J. Pyridinyl diradical pimer. Magnesium iodide complexes. J. Am. Chem. Soc. 1971, 93, 2534-2535; (d) Bird, C. L.; Kuhn, A. T. Electrochemistry of the viologens. Chem. Soc. Rev. 1981, 10, 49-82; (e) Bockman, T. M.; Kochi, J. K. Isolation and oxidation-reduction of methylviologen cation 
radicals. Novel disproportionation in charge-transfer salts by X-ray crystallography. J. Org. Chem. 1990, 55, 4127-4135.

(11) (a) Jeon, W.S.; Kim, H. J.; Lee, C.; Kim, K. Control of the stoichiometry in hostguest complexation by redox chemistry of guests: Inclusion of methylviologen in cucurbit[8]uril. Chem. Commun. 2002, 1828-1829; (b) Iordache, A.; Oltean, M.; Milet, A.; Thomas, F.; Baptiste, B.; Saint-Aman, E.; Bucher, C. Redox control of rotary motions in ferrocene-based elemental ball bearings. J. Am. Chem. Soc. 2012, 134, 2653-2671; (c) Buck, A. T.; Paletta, J. T.; Khindurangala, S. A.; Beck, C. L.; Winter, A. H. A noncovalently reversible paramagnetic switch in water. J. Am. Chem. Soc. 2013, 135, 10594-10597; (d) Zhang, L.; Zhou, T. Y.; Tian, J.; Wang, H.; Zhang, D. W.; Zhao, X.; Liu, Y.; Li, Z. -T. Poly. Chem. 2014, 5, 4715-4721.

(12) (a) Moon, K.; Grindstaff, J.; Sobransingh, D.; Kaifer, A. E. Cucurbit[8]urilmediated redox-controlled self-assembly of viologen-containing dendrimers. Angew. Chem. Int. Ed. 2004, 5496-5499; (b) Zhang, D.W.; Tian, J.; Chen, L.; Zhang, L.; Li, Z.-T. Dimerization of conjugated radical cations: An emerging noncovalent interaction for self-assembly. Chem. Asian. J. 2015, 10, 56-68; (c) Cai, K.; Lipke, M.C.; Liu, Z.; Nelson, J.; Cheng, T.; Shi, Y.; Cheng, C.; Shen, D.; Han, J. M.; Vemuri, S.; Feng, Y.; Stern, C. L.; Goddard III, W. A.; Wasielewski, W. R.; Stoddart, J. F. Molecular Russian dolls, Nat. Commun. 2018, 9, 5275.

(13) Li, H.; Fahrenbach, A. C.; Dey, S. K.; Basu, S.; Trabolsi, A.; Zhu, Z.; Botros, Y. Y.; Stoddart, J. F. Mechanical bond formation by radical templation. Angew. Chem. Int. Ed. 2010, 49, 8260-8265.

(14) Berville, M.; Richard, J.; Stolar, M.; Choua, S.; Le Breton, N.; Gourlaouen, C.; Boudon, C.; Ruhlmann, L.; Baumgartner, T.; Wytko, J. A.; Weiss, J. A highly stable organic radical cation. Org. Lett. 2018, 20, 8004-8008.

(15) Trabolsi, A.; Khashab, N.; Fahrenbach, A. C.; Friedman, D. C.; Colvin, M. T.; Cotí, K. K.; Benítez, D.; Tkatchouk, E.; Olsen, J. C.; Belowich, M. E.; Carmielli, R. H.; Khatib, A.; Goddard III, W. A.; Wasielewski M. R.; Stoddart, J. F. Radically enhanced molecular recognition. Nat. Chem. 2010, 2, 42-49.

(16) (a) Li, H.; Zhu, Z.; Fahrenbach, A. C.; Savoie, B. M.; Ke, C.; Barnes, J. C.; Lei, J.; Zhao, Y. L.; Lilley, L. M.; Marks, T. J.; Ratner, M. A. Mechanical bond-induced 
radical stabilization. J. Am. Chem. Soc. 2012, 135, 456-467; (b) Barnes, J. C.; Fahrenbach, A. C.; Cao, D.; Dyar, S. M.; Frasconi, M.; Giesener, M. A.; Benítez, D.; Tkatchouk, E.; Chernyashevskyy, O.; Shin, W. H.; Li, H.; Sampath, S.; Stern, C. L.; Sarjeant, A. A.; Hartlieb, K. J.; Liu, Z.; Carmieli, R.; Botros, Y. Y.; Choi, J. W.; Slawin, A. M. Z.; Ketterson, J. B.; Wasielewski, M. R.; Goddard III, W. A.; Stoddart, J. F. A radically configurable six-state compound. Science 2013, 339, 429-433; (c) Sun, J.; Liu, Z.; Liu, W. G.; Wu, Y.; Wang, Y.; Barnes, J. C.; Hermann, K. R.; Goddard III, W. A.; Wasielewski, M. R.; Stoddart, J. F. Mechanical-bondprotected, air-stable radicals. J. Am. Chem. Soc. 2017, 139, 12704-12709.

(17) Cai, K.; Shi, Y.; Vemuri, S.; Cao, C.; Cui, B.; Shen, D.; Wu, H.; Zhang, L.; Qiu, Y.; Chen, H.; Jiao, Y.; Stern, C. L.; Alsubaie, F. M.; Xiao, H.; Li, J.; Stoddart, J. F. Tuning radical interactions in trisradical tricationic complexes by varying hostcavity sizes. Chem. Sci. 2019, 11, 107-112.

(18)A bolded descriptor denotes a compound, be it free or complexed, and an unbolded descriptor refers to either (i) a component within a molecule or (ii) a component part of a mechanically interlocked molecule.

(19) Since the first reduction potential of $\mathbf{T E M V}^{2+}$ (Scheme 1) is around $+0.27 \mathrm{~V}$ versus $\mathrm{Ag} / \mathrm{AgCl}$, we believe that, if the second reduction potentials of the new [2] catenanes are more positive than $+0.27 \mathrm{~V}$, then their bisradical states will have comparable or even better air-stability than TEMV ${ }^{\bullet+}$.

(20) The previously reported protocol in Reference $16 \mathrm{~b}$ uses $\mathrm{Zn}$ dust as the reducing agent to generate rapidly the trisradical tricationic complexes. Zn dust, however, must be removed from the reaction mixture before BIPY is added to the solution so as to react with the encapsulated xylylene dibromide. Zn will over-reduce the viologen radical cation to give its neutral state if it remains in the reaction mixture. Once the substitution is over, however, the newly formed BIPY ${ }^{2+}$ cannot be reduced because of the absence of reducing reagents in the solution. Hence, there will be fast electron exchange between the newly formed BIPY ${ }^{2+}$ units and the trisradical tricationic complexes, a situation which will reduce the formation of the trisradical tricationic complexes and therefore decrease the catenation yield. The advantage of using $\mathrm{Cu}$ dust is that it can remain in the reaction mixture with no threat of over- 
reduction, and can reduce continuously the newly formed $\mathrm{BIPY}^{2+}$ units to radical cations.

(21) Wang, Z.; Qian, G. Near-infrared organic compounds and emerging applications. Chem. Asian J. 2010, 5, 1006-1029.

(22) Sun, Z.; Ye, Q.; Chi, C.; Wu, J. Low band gap polycyclic hydrocarbons: from closed-shell near infrared dyes and semiconductors to open-shell radicals. Chem. Soc. Rev. 2012, 41, 7857-7889.

(23) (a) Lü, B.; Chen, Y.; Li, P.; Wang, B.; Müllen, K.; Yin, M. Stable radical anions generated from a porous perylenediimide metal-organic framework for boosting near-infrared photothermal conversion. Nat. Commun. 10, 767; (b) Tang, B.; Li, W. L.; Chang, Y.; Yuan, B.; Wu, Y.; Zhang, M. T.; Xu, J. F.; Li, J.; Zhang, X. A supramolecular radical dimer: High-efficiency NIR-II photothermal conversion and therapy. Angew. Chem. Int. Ed. 2019, 58, 15526-15531.

(24) (a) Yao, C. J.; Zhong, Y. W.; Nie, H. J.; Abruna, H. D.; Yao, J. Near-IR electrochromism in electropolymerized films of a biscyclometalated ruthenium complex bridged by 1, 2, 4, 5-tetra (2-pyridyl) benzene. J. Am. Chem. Soc. 2011, 133, 20720-20723; (b) Cai, K.; Yan, Q.; Zhao, D. Large hydroazaacene diimides: synthesis, tautomerism, halochromism, and redox-switchable NIR optics, Chem. Sci. 2012, 3, 3175-3182; (c) Keshri, S. K.; Asthana, D.; Chorol, S.; Kumar, Y.; Mukhopadhyay, P. Appending diverse $\pi$-extended acceptors with tetrathiafulvalene/dithiafulvalene donors: multistate redox properties, radical ion generation, and mid-IR-absorbing mixed-valence states. Chem. Eur. J. 2018, 24, 1821-1832.

(25) Cui, B. B.; Tang, J. H.; Yao, J.; Zhong, Y. W. A molecular platform for multistate near-infrared electrochromism and flip-flop, flip-flap-flop, and ternary memory. Angew. Chem. Int. Ed. 2015, 54, 9192-9197. 

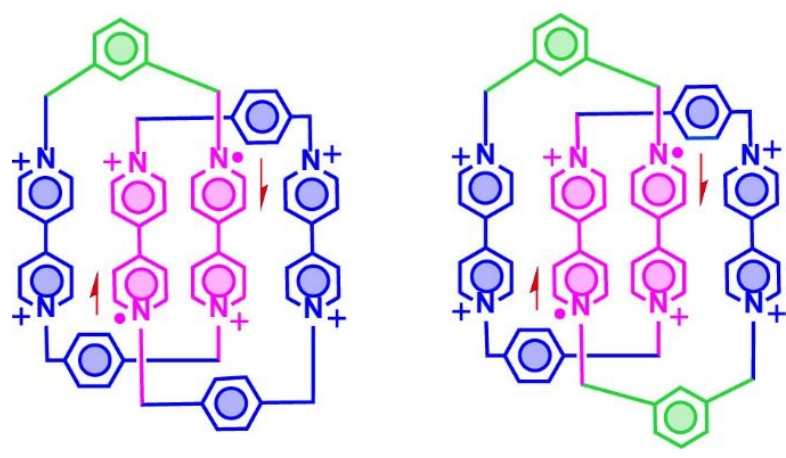

\section{Table of Contents}

